\title{
Escherichia coli Bacteremia-induced Purpura Fullminans: A Case Report
}

\author{
Mohamed Ahmed ${ }^{1}$, Michael Samotowka ${ }^{2}$, Saba Habis ${ }^{3}$, Ahmed Mahmoud ${ }^{1}$, Rasha Saeed ${ }^{4}$ \\ 1. Surgery, Riverside Community Hospital / Envision Healthcare, Riverside, USA 2. Surgery, Jackson Memorial \\ Hospital, Jacksonville, USA 3. Internal Medicine, Riverside Community Hospital / Hospital Corporation of America, \\ Riverside, USA 4. Surgery, Riverside Community Hospital / University of California, Riverside, USA
}

Corresponding author: Mohamed Ahmed, maamsmd@yahoo.com

\begin{abstract}
Purpura fulminans (PF) is a dermatologic manifestation of an underlying life-threatening condition associated with disseminated intravascular coagulation and skin necrosis. The known categories include protein $\mathrm{C}$ deficiency or abnormalities of other coagulation systems (inherited or acquired), acute infectious PF and idiopathic. We describe a case of PF induced by Escherichia coli-associated bacteremia.
\end{abstract}

Categories: Dermatology, General Surgery, Infectious Disease

Keywords: purpura fulminans, escherichia coli, disseminated intravascular coagulation

\section{Introduction}

Purpura fulminans (PF) was first described by Guelliot in 1884 [1]. It is a life-threatening condition associated with disseminated intravascular coagulation (DIC) and skin necrosis that progresses rapidly to multi-system organ failure secondary to thrombotic occlusion of small- and medium-sized blood vessels [2]. Herein, we describe a case of intestinal Escherichia coli -associated bacteremia as a part of PF syndrome.

\section{Case Presentation}

A 62-year-old Hispanic male was admitted to the intensive care unit (ICU) with signs of septic shock. After an aggressive fluid resuscitation and administration of intravenous antibiotics including vancomycin and Zosyn, a computed tomography (CT) scan of the abdomen and pelvis was obtained revealing coloenteritis (Figure 1).

\author{
Received 11/14/2018 \\ Review began 11/16/2018 \\ Review ended 11/22/2018 \\ Published 11/26/2018 \\ ๑) Copyright 2018 \\ Ahmed et al. This is an open access \\ article distributed under the terms of the \\ Creative Commons Attribution License \\ CC-BY 3.0., which permits unrestricted \\ use, distribution, and reproduction in any \\ medium, provided the original author and \\ source are credited.
}




\section{Cureus}

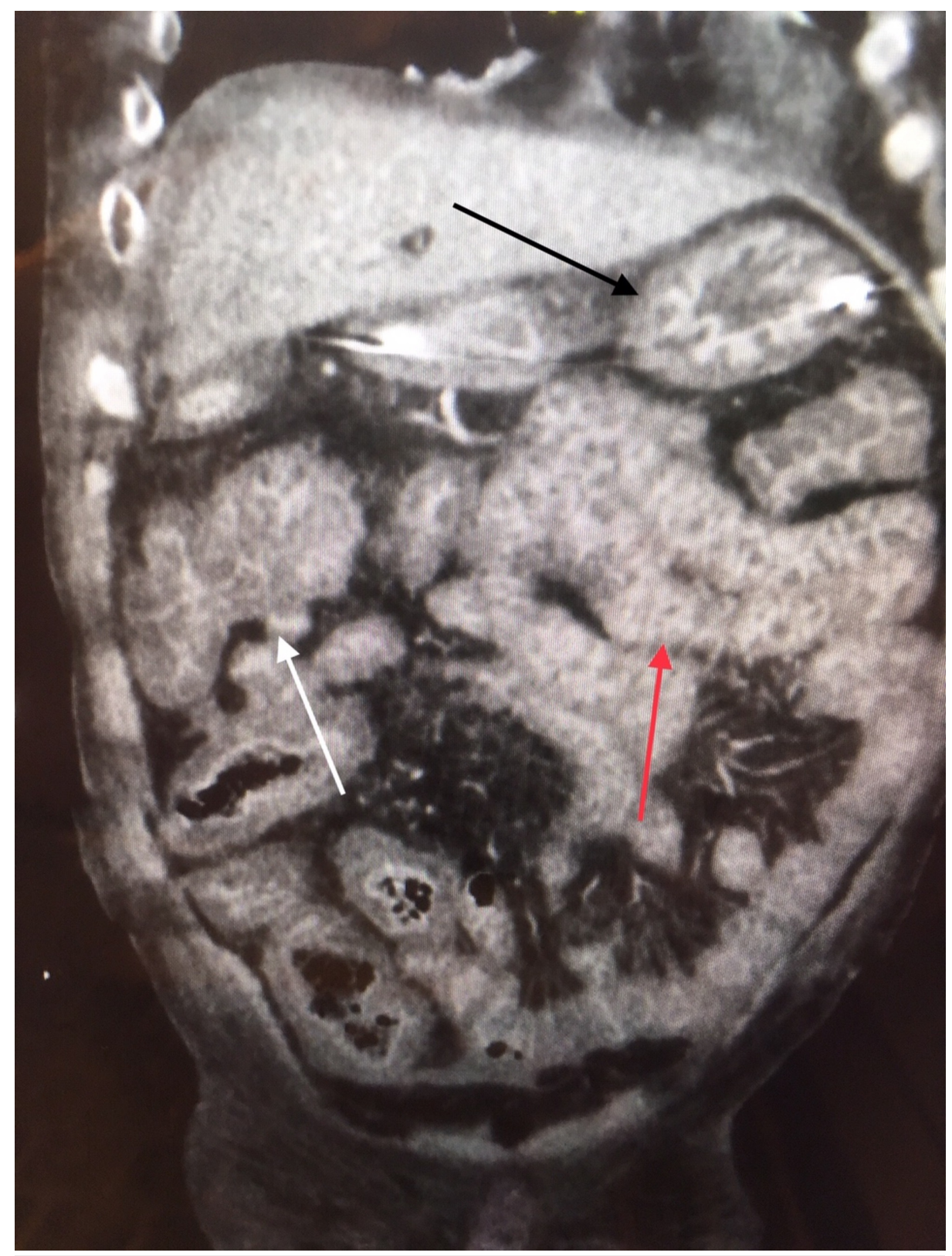

\section{FIGURE 1: CT abdomen and pelvis}

Black arrow: inflamed stomach; white arrow: inflamed colon; red arrow: inflamed small bowel

CT: computed tomography

His course was complicated by DIC requiring transfusion of blood products, along with ventilatory support for hypoxic respiratory failure and beta-blocker medications for controlling the atrial fibrillation rate. Blood cultures grew E.coli, and antibiotic coverage was changed to meropenem and ceftriaxone. The patient developed bilateral flank dark-red discoloration and bullous lesions with copious weeping. Skin lesions progressed rapidly to full-thickness necrosis in spite of local wound care with topical silver sulfadiazine (Figure 2). 


\section{Cureus}

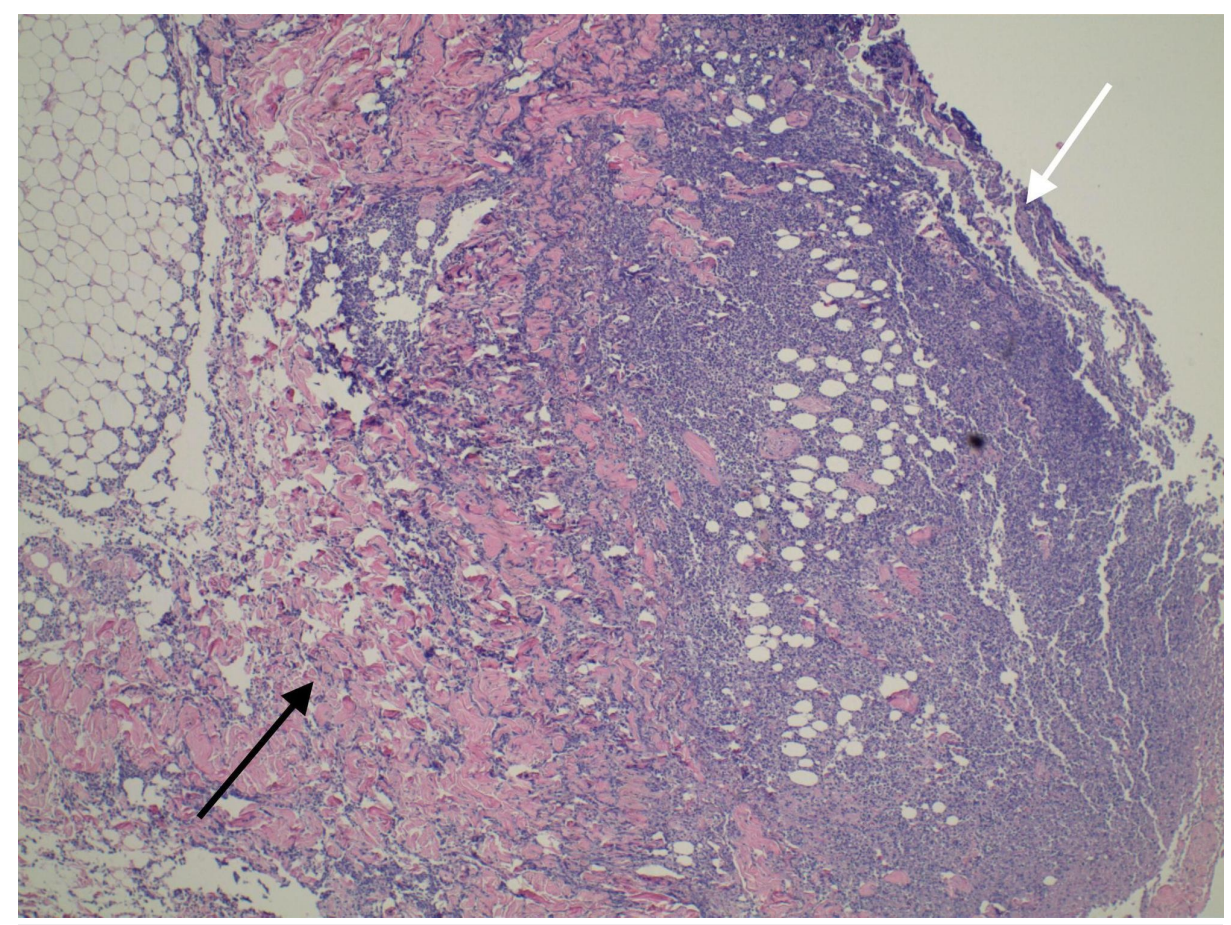

\section{FIGURE 2: Skin histopathology}

White arrow: necrotic skin; black arrow: inflammatory changes

The differential diagnoses (Coumadin-induced necrosis, thrombotic thrombocytopenic purpura, meningococcemia, toxic shock syndrome, calciphylaxis, necrotizing fasciitis and meningococcemia) were all ruled out. Necrotic skin and subcutaneous tissues required multiple surgical excisions, debridement and the use of a wound vacuum (Figure 3). 


\section{Cureus}

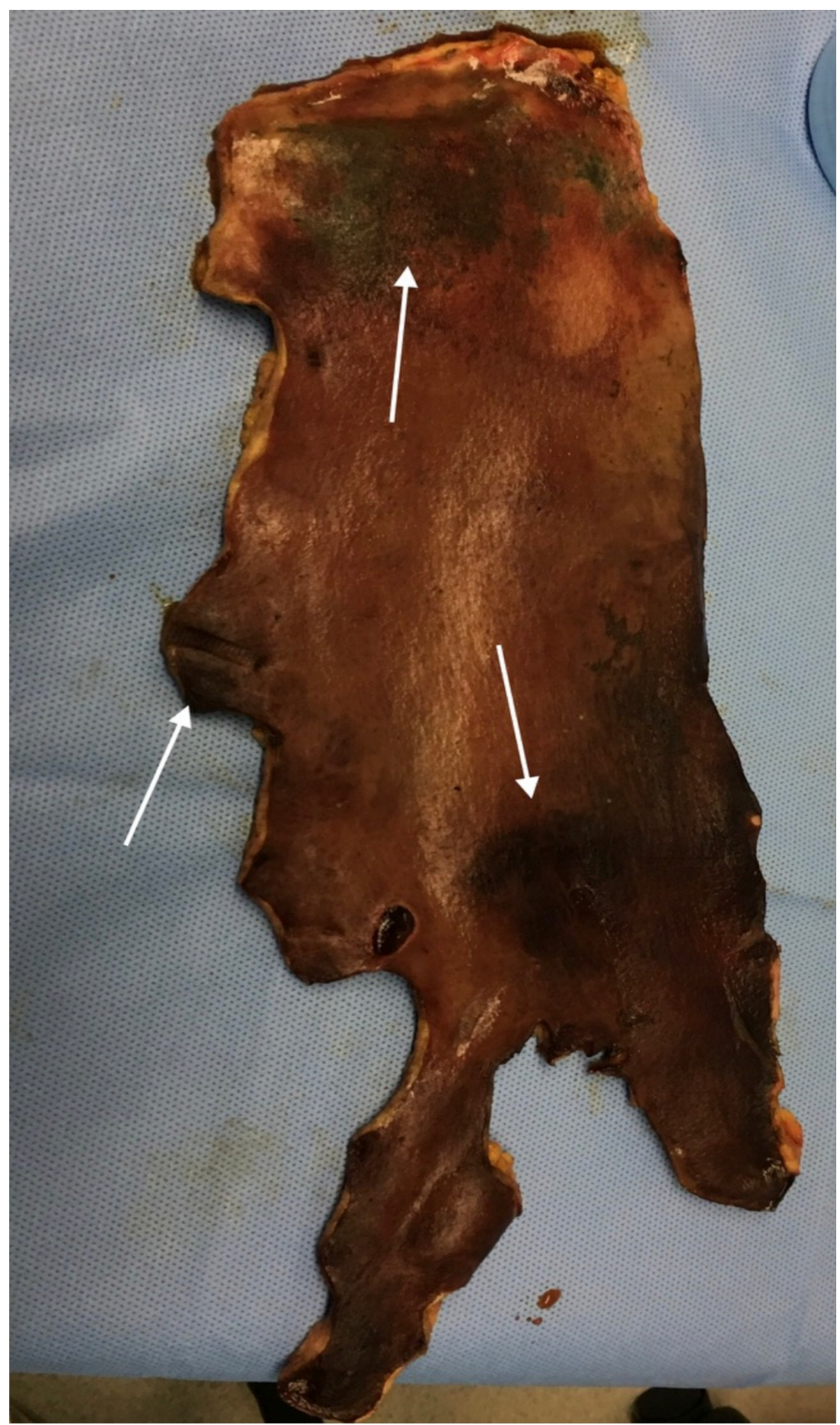

FIGURE 3: Excised necrotic skin

White arrow: necrotic skin

After a prolonged hospital stay with multidisciplinary care, local wound care and skin grafting, the patient did well and was discharged to an acute rehabilitation center (Figure 4). 


\section{Cureus}

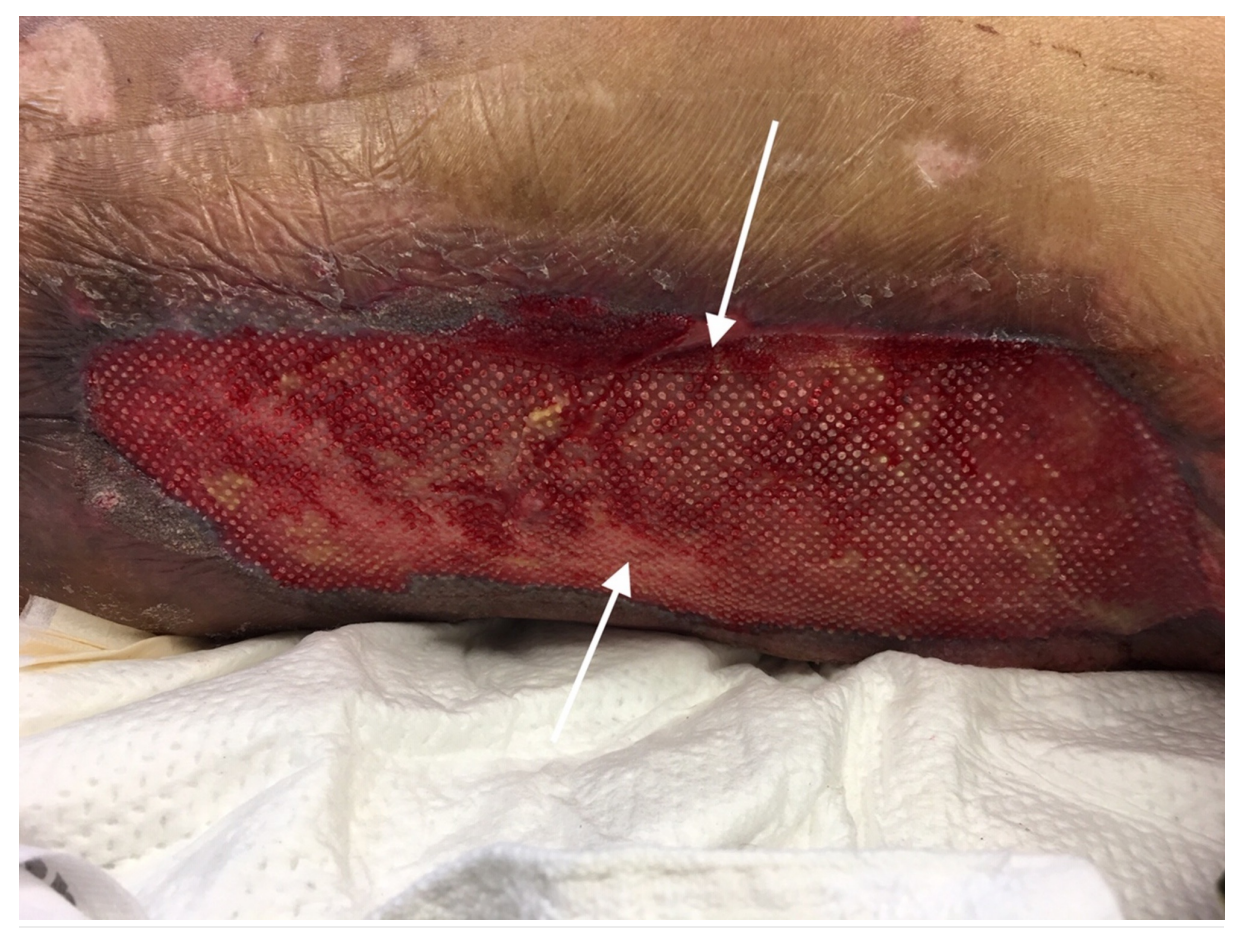

\section{FIGURE 4: Skin grafting}

White arrow: skin graft

\section{Discussion}

PF is a cutaneous manifestation of an underlying sudden and severe DIC. Retiform purpura and skin necrosis develop as a result of the coagulopathies typical of DIC. The pathogenesis probably involves acute transient decreases in the levels of protein C, protein S, or antithrombin III (ATIII). It is categorized into protein $\mathrm{C}$ deficiency or abnormalities of other coagulation systems (inherited or acquired) abnormalities, acute infectious PF and idiopathic. Inherited causes are secondary to homozygous protein C or S deficiency although heterozygous has also been described. Antecedent infections commonly include Neisseria meningitidis, group A Streptococcus, Staphylococcus, Pneumococcus, Vibrio, Meningococcus and Varicella; however; E. coli-associated bacteremia has been reported [3-4]. Although E.coli is typically not an antecedent infectious agent, both intestinal [5] and extra-intestinal infections caused by E.coli have been reported [6-7]. Early recognition and treatment of PF are essential to reduce mortality, and management is tailored to the individual patient. It involves supportive therapy and replacement of blood products and clotting factors as appropriate, and in cases of septicemia, aggressive resuscitation and antibiotics are important [8-9]. Heparin may reverse skin necrosis, protein $\mathrm{C}$ may contribute to improved survival, antithrombin III may reverse DIC [10], recombinant tissue plasminogen activator (rtPA) can improve peripheral perfusion [11], topical nitroglycerin may improve skin blood flow and pain, plasmapheresis removes circulating endotoxin and assists in controlling fluid balance, epidural sympathetic block with local anesthetic can improve skin perfusion [12], necrotic skin and tissues can be managed by excisional debridement and local wound care and in cases of extensive loss, skin grafting is performed [13].

\section{Conclusions}

$\mathrm{PF}$ is a morbid and potentially fatal condition that can be a cutaneous manifestation of $E$. Coli bacteremia. Early recognition and accurate identification of the underlying cause minimize morbidity and mortality. Management is tailored to the individual patient and in our case, aggressive early resuscitation, intravenous antibiotics, correction of coagulopathy, necrotic skin excision and, later, grafting were required.

\section{Additional Information}

\section{Disclosures}

Human subjects: Consent was obtained by all participants in this study. Conflicts of interest: In compliance with the ICMJE uniform disclosure form, all authors declare the following: Payment/services info: All authors have declared that no financial support was received from any organization for the submitted work. Financial relationships: All authors have declared that they have no financial relationships at present or within the previous three years with any organizations that might have an interest in the submitted work. Other relationships: All authors have declared that there are no other 


\section{References}

1. D'Cruz D, Cervera R, Olcay A, Ahmed T, Front J, Hughes GRV: Systemic lupus erythematosus evolving into systemic vasculitis: a report of five cases. J Rheum. 1993, 32:154-7.

2. Kondaveeti S, Hibberd M, Booy R, Nadel S, Levin M: Effect of the factor V Leiden mutation on the severity of meningococcal disease. Pediatr Infect Dis J. 1999, 18:893-6. 10.1097/00006454-199910000-00011

3. Amara M, Bonacorsi S, Bedel J, et al.: Group A Escherichia coli-related Purpura Fulminans: an unusual manifestation due to an unusual strain?. J Clin Microbiol. 2014, 52:4404-06. 10.1128/JCM.01362-14

4. Huemer GM, Bonatti H, Dunst KM: Purpura fulminans due to E. coli septicemia. Wien Klin Wochenschr. 2004, 116:82. 10.1007/BF03040700

5. Helviz Y, Hersch M, Shmuelevitz L, Atrash J, Einav S: Bad to worse. Am J Med. 2011, 124:215-17.

6. Russo TA, Johnson JR: Medical and economic impact of extraintestinal infections due to Escherichia coli: focus on an increasingly important endemic problem. Micro and Inf. 2003, 5:449-56. 10.1016/S12864579(03)00049-2

7. De Kraker M, Jarlier V, Monen J, Heuer OE, van de Sande N, Grundmann H: The changing epidemiology of bacteraemias in Europe: trends from the European Antimicrobial Resistance Surveillance System. CMI. 2013, 19:860-8. 10.1111/1469-0691.12028

8. Rintala E, Kauppila M, Seppälä O, Voipio-Pulkki LM, Pettilä V, Rasi V, Kotilainen P: Protein C substitution in sepsis-associated purpura fulminans. Crit Care Med. 2000, 28:2373-8. https://www.ncbi.nlm.nih.gov/pubmed/10921567.

9. Francis RB Jr: Acquired purpura fulminans. Semin Thromb Hemost. 1990, 16:310-25. 10.1055/s-20071002684

10. Nolan J, Sinclair R: Review of management of purpura fulminans and two case reports . Br J Anaesth. 2001, 86:581-6. 10.1093/bja/86.4.581

11. Aiuto LT, Barone SR, Cohen PS, Boxer RA: Recombinant tissue plasminogen activator restores perfusion in meningococcal purpura fulminans. J Crit Care Med. 1997, 25:1079-82.

12. Freise H, Meissner A, Lauer S, et al.: Thoracic epidural analgesia with low concentration of bupivacaine induces thoracic and lumbar sympathetic block: a randomized, double-blind clinical trial. Anesthesiology. 2009, 111:1249-56. 10.1097/ALN.0b013e31818db16c

13. Basta M, Bronze M: Purpura fulminans treatment \& management . Medscape J Med. 2018, 